\title{
LETTERS
}

\section{Do not postpone discussing advanced directives}

In her CMAJ Humanities article, Dr. Susan MacDonald ${ }^{1}$ relates the sad and emotionally charged situation of her quiet and reclusive patient with advanced incurable cancer requiring hydromorphone, taking an overdose. The patient ended up with an undignified failed resuscitation in an emergency room surrounded by a host of staff who would have been strangers to him. Losing a patient to suicide is traumatic, not least to the doctors involved in their care. I sympathize with Dr. MacDonald because she would be sharing in this grief along with the family.

A regret that I sometimes have in patients with a poor medical prognosis, for whatever diagnosis, is that advanced directives had not been discussed with respect to an expected natural death at home or to their feelings about resuscitation. Should a patient of sound mind elect not to be resuscitated, then this would need to be respected even with a suicide attempt. I realize that this raises ethical issues for which legal counsel may be required in advance in certain cases, but a do-not-resuscitate order will also enable a more peaceful death. When a natural death does not seem imminent, discussions of this nature are often, unfortunately, postponed.

\section{Graham White MD}

Family medicine physician, Portage

Medical Clinic, Portage la Prairie, Man.

Cite as: CMAJ 2019 July 15;191:E796.

doi: $10.1503 / \mathrm{cmaj} .72212$

\section{Reference}

1. MacDonald S. Leo died the other day. CMAJ 2019;191:E49-50.

Competing interests: None declared. 